\title{
MRI Findings of Borderline Retroperitoneal Serous Cystadenocarcinoma
}

\author{
Gurcan Erbay,1 Elif Karadeli1 and Alper Parlakgumus²
}

\begin{abstract}
Retroperitoneal serous cystadenocarcinoma is an extremely uncommon lesion. Here, we present MR imaging findings of a 40-year woman who was admitted to the hospital due to abdominal pain. The patient was evaluated with abdominal Computed Tomography (CT) and Magnetic Resonance Imaging (MRI). Abdominal CT revealed a $13 \times 18 \mathrm{~cm}$ large retroperitoneal and cystic mass with polypoid projections. MRI was superior than $\mathrm{CT}$ in showing polypoid projections. Contrast enhanced MRI detected enhancement of thin septations and cyst appearance inner the cyst. Diffusion-weighted MRI showed restricted diffusion in the polypoid component with contrast enhancement. Therefore, we thought malignant lesion. The findings of contrast-enhanced CT and MRI were helpful in the diagnosis of those lesions. In addition, diffusionweighted MRI with multiparametric modalities played unlimited role in the assesment of the differential diagnosis.
\end{abstract}

Key Words: Diffusion-weighted magnetic resonance imaging, Retroperitoneal neoplasm, Cystadenocarcinoma, Serous.

\section{INTRODUCTION}

Retroperitoneal cystic lesions are uncommon. The incidence of these isolated lesions are ranged between $1 / 5,750$ to $1 / 250,000 .{ }^{1}$ There are abdominal complaints related to size among two-thirds of lesions; whereas, others are asymptomatic, and are detected as an incidental finding. 2,3

The retroperitoneal cystic lesions may be neoplastic or nonneoplastic. Non-neoplastic lesions are mesenteric, omental cysts, splenic and enteric duplication cysts. Neoplastic lesions are epithelial (serous/mucinous cystadenomaadenocarcinoma), germ cell tumor, other tumors containing cystic areas (paraganglioma, nörilemmoma, sarcoma). Epidermoid cyst, lyphangioma, mullerian cyst, epidermoid cyst, tailgut cyst, broncogenic cyst, pseuodomyxoma retroperitonei, and perianal mucinous cyst adenoma are rarely seen tumors. ${ }^{2-5}$

Retroperitoneal serous cystadenocarcinoma is an extremely uncommon lesion of retroperitoneum. Therefore, we present a case of a 40-year woman with MRI findings of the large retroperitoneal cystic lesion.

\section{CASE REPORT}

A 40-year married woman, presented with severe abdominal pain, was examined at our hospital. She had myomectomy 6 years ago, but had no trauma or acute

Department of Radiologyl / General Surgery², Baskent

University School of Medicine, Dr. Turgut Noyan Medical and Research Center, Adana, Turkey

Correspondence: Dr. Alper Parlakgumus, Department of General Surgery, Baskent University School of Medicine,

Dr. Turgut Noyan Medical and Research Center, Adana, Turkey

E-mail: aparlakgumus@yahoo.com

Received: February 16, 2018; Accepted: July 03, 2018 pancreatitis. The results of patient's laboratory tests including white blood cell count, CA-19-9, and CEA levels were normal. CA-125 antigen was mild high, 49,9 IU (normal range, 0 to 30,2 IU). Abdominal contrast enhanced computed tomography revealed a $13 \times 18 \mathrm{~cm}$ large retroperitoneal and cystic mass with polypoid projections at the inferior component. The lesion had no calcification. The right kidney was displaced to anterior and superior.

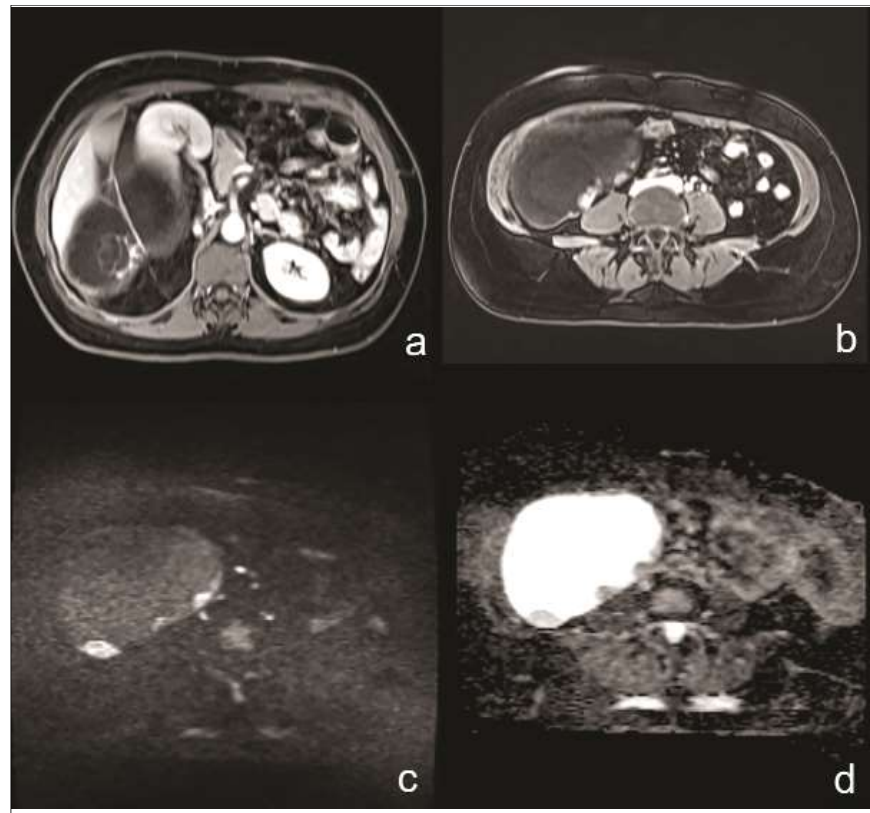

Figure 1: (a) Axial contrast-enhanced T1-weighted magnetic resonance image shows a cyst into retroperitoneal cyst containing thin septations, and noduler, papillary projections. The right kidney was displaced to anterior and superior.

(b) There are polypoid projections extented to lumen on axial contrastenhanced T1-weighted magnetic resonance image.

(c) Axial diffusion-weighted magnetic resonance image on b-1000 value shows hyperintense polypoid lesions.

(d) ADC map obtained with diffusion-weighted magnetic resonance images shows hypointense signal consistent with restricted diffusion. 
MRI was superior than CT in the showing polypoid projections. Contrast enhanced MRI detected enhancement of thin septations and cyst appearance inner the cyst (Figures 1a, 1b). Diffusion-weighted MRI showed restricted diffusion in the polypoid component with contrast enhancement. Therefore, we thought malignant lesion (Figures 1c, 1d). After laparoscopic surgery, the histopathological diagnosis of lesion was detected as borderline serous cystadenocarcinoma.

\section{DISCUSSION}

Approximately $70 \%$ of the primary retroperitoneal tumors in adults are usually malignant and prevalance of these tumors are less than 1\%.6-8 These tumors may be neoplastic or non-neoplastic. The neoplastic lesions at the retroperitoneal location are cystadenomas, mesotheliomas, and cystic degeneration with solid lesions. Whereas, non-neoplastic lesions are urinomas, haematomas, lymphoceles, pseudocysts. 3,4

They usually have big size at the time of diagnosis, because of the compliance of the growing space is large. $\mathrm{CT}, \mathrm{MRI}$ and US are important tools in the diagnosis and following of the retroperitoneal cystic lesions. Ultrasound may detect this lesion, but it is insufficient in the showing of its extention and relationship with surrounding organs. The local recurrence of the lesions are higher than that of the metastases. $6 \mathrm{MRI}$ has superior contrast resolution, therefore, MRI findings are more successful than the CT images. ${ }^{6-8}$ When these cystic lesions are large, it can be difficult to identify of orgin of lesions with imaging methods. The CT and MRI findings as beak sign, embedded organ sign, phantom organ sign, predominant feedining artery sign give us important clues. ${ }^{4}$ Especially, MRI plays an important role in the evaluation of the fat, water, calcification contents and vascularity in the lesion. Appropriate MRI sequences and new generation machines are helpful in the showing of the lesions. Diffusion-weighted MRI shows restricted diffusion. This finding and abnormal contrast enhancement on MRI points out possibility of malignancy.

Serous cystadenocarcinomas are rarely seen. There are three theories in the development of these lesions: the first is serous or mucinous metaplasia of retroperitoneal coelomic mesothelium related routes of ovarian descent. Other theories about development of serous cystadenocarcinomas are an enterogenous cyst, a teratoma and a supernumerary ovary. 9,10

The CT and MRI findings of these lesions are usually non-specific. The solid, intramural nodule, enhancement of septation and nodule, and high CEA level are important; and these findings are helpful in the diagnosis of the retroperitoneal cystic lesions. ${ }^{3}$

Different from the literature knowledge, there was no high CEA level, as only CA-125 antigen level was high in our case. The findings of our case were enhancement of the solid component and papillary projections into the lumen. In addition, restricted diffusion as distinct from literature was detected.

In conclusion, serous cystadenoma and serous cystadenocarcinoma are rare tumours. But, contrastenhanced CT and MRI are helpful in the diagnosis of these lesions. In addition, diffusion-weighted MRI with multiparametric modalities has unlimited role in the assesment of the differential diagnosis.

\section{REFERENCES}

1. Izaraa A, Mousa H, Dickens P, Allen J, Benhamida A. Idiopathic benign retroperitoneal cyst: a case report. J Med Case Rep 2008; 2:43.

2. Yang DM, Jung DH, Kim H, Kang JH, Kim SH, Kim JH, et al. Retroperitoneal cystic masses: CT, clinical and pathological findings and literature review. Radiographics 2004; 24:353-65.

3. Rajiah P, Sinha R, Cuevas C, Dubinsky T, Bush W, Kolokythas O. Imaging of uncommon retroperitoneal masses. Radiographics 2011; 31:949-76.

4. Mori A, Changela K, Alhankawi D, Itskovich A, Butt A, Reddy M. A giant primary retroperitoneal serous cystadenoma: Case report and review of retroperitoneal cysts. Surg J (NY) 2017; 16:e32-7.

5. Nishino M, Hayakawa K, Minami M, Yamamoto A, Ueda $H$, Takasu K. Primary retroperitoneal neoplasms: CT and MR findings with anatomic and pathologic diagnostic clues. Radiographics 2003; 23:45-57.

6. Neville A, Herts BR. CT characteristics of primary retroperitoneal neoplasms. Crit Rev Comput Tomogr 2004; 45:247-70.

7. Shanbhogue AK, Fasih N, Macdonald DB, Sheikh AM, Menias CO, Prasad SR. Uncommon primary pelvic retroperitoneal masses in adults: A pattern-based imaging approach. Radiographics 2012; 32:795-817.

8. Koh DM, Moskovic E. Imaging tumours of the retroperitoneum. Imaging 2000; 12:49-60.

9. Arichi N, Yasumoto H, Mitsui Y, Hiraoka T, Honda S, Shiina H, et al. A case of primary retroperitoneal serous adenocarcinoma. Int J Urol 2011; 18:844-6.

10. Kaku M, Ohara N, Seima Y, Imanishi K, Tomura N, Kobayashi A, et al. A primary retroperitoneal serous cystadenocarcinoma with clinically aggressive behavior. Arch Gynecol Obstet 2004; 270:302-6. 